\title{
Pengaruh Motivasi Kerja Terhadap Kinerja Karyawan dengan Organizational Citizenship Behavior sebagai Mediasi
}

\author{
Karina Debbie Gautama dan Edalmen \\ Program Studi Manajemen Fakultas Ekonomi \& Bisnis \\ Universitas Tarumanagara \\ Email: karinadebbies@gmail.com
}

\begin{abstract}
This study aims to determine the effect of work motivation on employee performance with organizational citizenship behavior $(O C B)$ employees as a mediating variable. The population in this study were all 42 employees of PT Corpus Prima Mandiri Sekuritas. The sample selection method uses a sampling technique saturated with quantitative research and uses a questionnaire to collect data. The results of the study show that there is a positive and significant influence of work motivation and organizational citizenship behavior on employee performance.And then work motivation has a positive and significant effect on organizational citizenship behavior. This study found that direct organizational citizenship behavior mediates the relationship between work motivation and employee performance.
\end{abstract}

Keywords: Organizational Commitment, Organizational Citizenship Behavior and Knowledge Sharing.

Abstrak: Penelitian ini bertujuan untuk mengetahui pengaruh motivasi kerja terhadap kinerja karyawan dengan organizational citizenship behavior (OCB) karyawan sebagai variabel mediasi. Populasi dalam penelitian ini adalah seluruh karyawan PT Corpus Prima Mandiri Sekuritas yang berjumlah 42 orang. Metode pemilihan sampel menggunakan teknik sampling jenuh dengan penelitian kuantitatif dan menggunakan kuesioner untuk mengumpulkan data. Hasil penelitian menunjukkan bahwa motivasi kerja dan organizational citizenship behavior berpengaruh positif dan signifikan terhadap kinerja karyawan. Dan kemudian motivasi kerja berpengaruh positif dan signifikan untuk organizational citizenship behavior. Penelitian ini menemukan bahwa secara tidak langsung, organizational citizenship behavior memediasi hubungan antara motivasi kerja terhadap kinerja karyawan.

Kata kunci: Motivasi Kerja, Organizational Citizenship Behavior dan Kinerja Karyawan

\section{LATAR BELAKANG}

Pembangunan bidang Sumber Daya Manusia (SDM) di Indonesia bertujuan untuk menciptakan sumber daya manusia yang berkualitas dan masyarakat yang lebih sejahtera. Peningkatan kualitas SDM menuntut individu dan kelompok untuk meningkatkan kinerjanya. Setiap perusahaan dituntut untuk menggunakan sumber daya yang dimilikinya dengan seoptimal mungkin. Artinya keunggulan yang kompetitif harus diciptakan oleh perusahaan melalui pengelolaan sumber daya manusia secara efektif dan efisien yang akan dapat membantu perusahaan untuk bersaing dengan para kompetitornya. Oleh sebab itu, karyawan yang dimiliki hendaknya dikelola agar dapat bekerja dan menjalankan roda dalam perusahaan dengan baik dan perusahaan akan mudah mendapatkan berbagai keuntungan seperti tercapainya visi dan misi perusahaan, mendapatkan keuntungan dan pendapatan yang sesuai target, atau dapat menaikan pangsa pasar dibanding para kompetitor. Sebaliknya, jika karyawan tidak dikelola dengan baik, maka karyawan akan bekerja tidak optimal sehingga dapat menimbulkan kerugian bagi perusahaan itu sendiri. Oleh sebab itu, perusahaan harus 
dapat mengelola SDM yang dimilikinya secara profesional agar dapat menghasilkan suatu kinerja dari karyawannya.

Salah satu program perwujudan dari perusahaan adalah menghasilkan suatu kinerja dari karyawan untuk dapat mencapai visi dan misi perusahaan. Kinerja pegawai merupakan sesuatu yang penting (Moeheriono, 2012), karena diyakini dapat mendorong tercapainya kemajuan dan tujuan sehingga perusahaan dapat bersaing dengan para kompetitornya dalam suatu persaingan global yang tidak stabil. Karyawan yang serius melaksanakan tugas serta tanggung jawabnya merupakan bukti adanya kinerja karyawan. Untuk dapat mengukur kinerja karyawannya, perusahaan dapat membuat suatu standar keberhasilan perusahaan bagi individu atau kelompok. Semakin tinggi kinerja perushaan semakin tinggi peningkatkan efektivitas dan efisiensi dalam penyelenggaraan pekerjaan yang dilakukan karyawan sehingga mudah untuk mencapai tujuan perusahaan. Beberapa faktor yang mempengaruhi kinerja individu menurut Wirawan (2009) yaitu gaya kepemimpinan dan motivasi kerja pegawai.

Motivasi merupakan indikator yang mampu membuat seorang pekerja lebih puas dalam menjalankan aktivitasnya. Motivasi memiliki hubungan yang erat dengan sikap dan perilaku seseorang. Emosi dapat dipengaruhi dan diubah oleh perilaku. Kekuatan yang ada dalam pikiran manusia melalui perubahan sikap dapat membantu dalam mengadaptasi, mempelajari, dan memproses setiap informasi dan perubahan baru yang diterimanya. Motivasi menurut Bangun (2012) mendorong karyawan untuk mau melaksanakan pekerjaannya dengan lebih baik lagi. Jika motivasi karyawan tinggi dalam melaksanakan pekerjaannya, maka akan menghasilkan kinerja yang baik dan tinggi juga. Hal ini menjelaskan bahwa semakin tinggi motivasi yang dimiliki karyawan, semakin tinggi kinerjanya.

Perusahaan yang sukses memerlukan karyawan yang mau mengerjakan tugas yang bukan termasuk tugas formal mereka sebagaimana dijelaskan oleh Organ, Podsakoff, \& Mackenzie (2006) sebagai perilaku karyawan yang dilakukan secara sukarela dan senang hati tanpa harus diperintah oleh kompensasi, dan hasilnya dapat menunjang kinerja organisasi. Hal ini yang kemudian dikenal dengan nama Organizational Citizenship Behavior (OCB). Organizational Citizenship Behaviour (OCB) menurut Robbins (2013) merupakan perilaku yang dipilih oleh karyawan, yang tidak menjadi kewajiban dari karyawan untuk melakukannya, dan dibutuhkan untuk mendukung fungsi organisasi secara efektif agar dapat dengan mudah mencapai tujuannya. Dengan adanya OCB, diyakini bahwa interaksi sosial di antara para anggota organisasi dapat mengurangi terjadinya perselisihan serta meningkatkan efektivitas dan efisiensi dalam kelompok. Contoh Organizational Citizenship Behavior (OCB) adalah melibatkan diri untuk menolong orang lain tanpa harus disuruh, menjadi volunteer, taat pada peraturan yang berlaku di tempat kerja, dan lain sebagainya. Karyawan yang memiliki OCB diyakini dapat menambah nilai tersendiri bagi dirinyadan dapat meningkatkan kinerja organisasinya.

Penelitian yang dilakukan oleh Rita dkk., (2017) menemukan adanyahubungan yang positif dan signifikan antara kepemimpinan transformasional, komitmen organisasi, dan motivasi yang di moderasi oleh Organizational Citizenship Behavior (OCB) terhadap kinerja karyawan. Penelitian yang dilakukan oleh Juniantara dan Riana (2015) menemukan bahwa motivasi kerja memiliki pengaruh yang positif dan signifikan terhadap kinerja karyawan. Hal senada juga ditemukan oleh Prasetio dan Wulansari (2016) bahwa motivasi memiliki pengaruh yang positif dan signifikan terhadap kinerja karyawan. Penelitian yang dilakukan oleh Hapsari (2015) menemukan bahwa motivasi kerja memiliki pengaruh yang positif dan signifikan terhadap Organizational Citizenship Behavior. Dan penelitian yang dilakukan oleh Florindo, dkk (2017) menemukan bahwa motivasi kerja memiliki pengaruh yang positif dan signifikan terhadap kinerja karyawan dengan Organizational Citizenship Behavior sebagai mediasi. 
PT Corpus Prima Mandiri Sekuritas adalah perusahaan manajemen dan keuangan yang terus berkembang, baik dalam kualitas dan integritas profesional di bidangnya dan terus menjadi salah satu perusahaan layanan konsultan yang terus berkembang. Dari laporan keuangan PT Corpus Prima Mandiri setiap tahun juga dapat dilihat adanya peningkatan, namun bukan kenaikan yang cukup tajam yang didapat. Peningkatan ini dirasa masih jauh dari target yang telah disepakati. Hal ini dapat dipengaruhi oleh kurang optimalnya pemberian motivasi dari perusahaan pada karyawannya, sehingga karyawan merasa kurang bergairah dalam melakukan kerja. Timbulnya kejenuhan karena rutinitas kerja yang monoton yang dilakukan setiap hari juga dapat menjadi penyebab kurangnya motivasi pada karyawan. Hal ini dapat mengakibatkan turunnya konsentrasi karyawan dalam bekerja.Perusahaan membutuhkan adanya pembaharuan pemberian motivasi bagi karyawan. Oleh sebab itu akanditeliti lebih lanjut mengenai motivasi kerja, Organizational Citizenship Behaviour (OCB) dankinerja karyawan di PT Corpus Prima Mandiri Sekuritas.

\section{KAJIAN TEORI}

Menurut Dessler (2017:293) "the continuous process of identifying, measuring, and developing the performance of individuals and teams and aligning their performance with organization's goals". Proses berkelanjutan mengidentifikasi, mengukur, mengembangkan kinerja individu dan tim serta menyelaraskan kinerja mereka dengan tujuan organisasi. Mangkunegara (2015) mengemukakan bahwa kinerja karyawan merupakan hasil kerja atau output yang dimana secara kualitas dan kuantitas dicapai oleh seorang pegawai dalam melaksanakan tugasnya sesuai dengan tanggung jawab yang diberikan. Kinerja karyawan menurut Viswesvaran \& Ones (2000) merupakan perilaku, tindakan dan hasil yang dapat diukur di mana karyawan terikat atau yang dilakukan karyawan yang berkontribusi pada tujuan organisasi dan berhubungan dengan tujuan organisasi.Definisi kinerja karyawan dapat disimpulkan peneliti sebagai suatu hasil kerja individu yang dihasilkan dalam melakukan kerja sesuai dengan tanggung jawab yang telah diberikan untuk pencapaian tujuan organisasi/perusahaan.

Menurut Meija, et al (2004), yang dikutip dari Javed (2013) motivasi dapat didefinisikan sebagai perilaku manusia yang senang, memiliki tujuan, dan berkelanjutan. Griffin (2014:90) mengemukakan bahwa motivasi kerja "is the set of forces that causes people to engage in one behavior rather than some alternative behavior". Seperangkat kekuatan yang menyebabkan orang untuk terlibat dalam satu perilaku daripada beberapa perilaku alternatif.Definisi motivasi kerja dapat penulis simpulkan sebagai suatu perilaku untuk mempengaruhi dan mendorong seseorang untuk melakukan sesuatu yang berkaitan dengan pekerjaan dalam pencapaian tujuan yang telah disepakati bersama dan dgunakan untuk memenuhi kebutuhannya.

Menurut Morrison (1994, h. 1545) “. . . an employee will be more likely to perform an activity if it is defined as in-role rather than extra-role implies that an important determinant of supervisory ratings of so-called $O C B$ will be how broadly employees define their job responsibilities". Maksud dari pernyataan ini adalah seorang karyawan akan melakukan suatu kegiatan apabila hal tersebut dianggap sebagai peran yang dimana akan menjadi peran tambahan tanpa melihat adanya imbalan.Organizational Citizenship Behavior (OCB) adalah perilaku karyawan melebihi tuntutan kerja dan mau turut serta berperan dalam kesuksesan organisasi (Richard, 2003). Perilaku OCB dapat ditunjukkan dengan membantu sesama rekan kerja, melakukan kerja tambahan jika dibutuhkan, dan membantu turut serta dalam pemecahan masalah.Berdasarkan pendapat di atasdisimpulkan bahwa OCB merupakan suatu 
perilaku yang timbul dalam diri seseorang yang dilakukan secara sukarela dan tidak merupakan bagian dari syarat pekerjaan formal.

Kinerja karyawan memegang sebuah peranan yang penting karena maju atau mundurnya perusahaan semua tergantung pada kinerja karyawan. Motivasi dianggap berhubungan erat dengan kinerja karena semakin tinggi motivasi, semakin mendorong karyawan untuk menghasilkan kinerja terbaiknya.OCB berkaitan dengan kinerja karyawan karena perilaku sukarela yang ditunjukkan karyawan akan mampu membantu meningkatkan efektivitas perusahaan dan mampu mempengaruhi aspek sosial dalam perusahaan. Semakin tinggi OCB yang dimiliki, semakin tinggi kinerja yang dihasilkan.

Berdasarkan Uraian tersebut maka terbentuk kerangka pemikiran dan hipotesis. Model Kerangka pemikiran dan hipotesis diuraikan sebagai berikut:

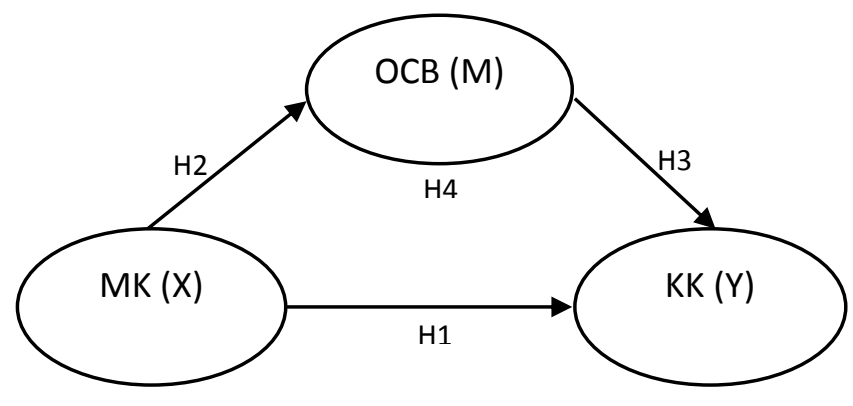

Gambar 1. Model Pemikiran

Berdasarkan kerangka pemikiran diatas, maka dapat dirumuskan hipotesis penelitian sebagai berikut:

$\mathrm{H}_{1}$ : Motivasi kerja memiliki pengaruh yang signifikan terhadap kinerja karyawan.

$\mathrm{H}_{2}$ : Motivasi kerja memiliki pengaruh yang signifikan terhadap Organizational Citizenship Behavior karyawan.

H3: Organizational Citizenship Behavior memiliki pengaruh yang signifikan terhadap kinerja karyawan.

H4: Motivasi kerja memiliki pengaruh yang signifikan terhadap kinerjakaryawan dengan Organizational Citizenship Behavior sebagai mediator.

\section{METODOLOGI}

Penelitian ini menggunakan desain penelitian kausal karena menguji hubungan sebab akibat antara motivasi kerja terhadap kinerja karyawan dengan organizational citizenship behavior (OCB) sebagai mediator yang dikaji menggunakan pendekatan penelitian kuantitatif (Sekaran \& Bougie, 2016: 96). Penelitian ini mengumpulkan data menggunakan kuesioner yang didukung oleh beberapa acuan teori dari para ahli dan menggunakan metode desktiptif dengan desain cross-sectional. Populasi pada penelitian ini adalah seluruh orang yang bekerja di PT Corpus Prima Mandiri Sekuritas dengan jumlah orang yang bekerja adalah 42 orang. Subjek yang diteliti adalah keseluruhan karyawan PT Corpus Prima Mandiri Sekuritas. Pengumpulan data dilakukan dengan menggunakan kuesioner yang disebar secara langsung ke karyawan PT Corpus Prima Mandiri Sekuritas dan tanggapannya diberikan skor berupa skala likert (Supriyanto \& Maharani, 2013: 43). Data dianalisis menggunakan PLS-SEM dimana data diolah dengan program software SmartPLS 3.0. 
Pertama, pengolahan dilakukan pada outer model untuk menguji validitas dan reliabilitas. Uji validitas dilihat dari nilai factor loading convergent validity pada variabel laten dengan indikator-indikatornya yang diharapkan > 0.7 (Hussein, 2015). Selanjutnya, Uji reliabilitas digunakan untuk menguji nilai reliabilitas dari setiap blok indikator yang mengukur sebuah konstruk, dimana konstruk dinyatakan reliabel (hasil pengukuran yang relatif sama dalam waktu yang berbeda) jika nilai cronbach's alpha $>0.6$ dan composite reliability > 0.7 (Lestariningtyas, 2016).

Kedua, pengolahan dilakukan pada inner model untuk menguji hipotesis yang telah dihasilkan. Sebelum pengujian hipotesis, pertama dilakukan pengujian besarnya pengaruh variabel independen terhadap variabel dependen dengan melihat nilai R-square (R2) berkisar dari 0 hingga 1, dimana 1 merepresentasikan akurasi prediktif yang sempurna (Hair et al.,2014). Predictive Relevance digunakan untuk menjelaskan relevansi dari inner model dalam penelitian. Konstruk endogen dinyatakan relevan untuk memprediksi model penelitian apabila memiliki nilai $\mathrm{Q}^{2}$ lebih dari 0 . Goodness of Fit (GoF) digunakan untuk menggambarkan tingkat kelayakan model secara keseluruhan. Nilai GoF diperoleh dari akar kuadrat dari average communalities index dikalikan dengan nilai rata-rata $\mathrm{R} 2$ model dan terbentang dari $0-1$ dengan interpretasi nilai yang dibagi menjadi tiga, nilai $\mathrm{GoF}=0,1$ (kecil), $\mathrm{GoF}=0,25$ (sedang) dan $\mathrm{GoF}=0,38$ (besar). Pengujian hipotesis, untuk melihat pengaruh yang terjadi lihat (positif/ negatif) dari coefficient yang dihasilkan, dan menggunakan t-statistics > 1,96 (hipotesis tidak ditolak) dan p-values $<0,05$ (hipotesis signifikan) (Ghozali dan Latan, 2015:42).

Variabel dan jumlah pernyataan yang digunakan dan yang akan diolah datanya dalam penelitian ini, tersaji dalam tabel 1 berikut ini:

Tabel 1. Operasionalisasi Variabel

\begin{tabular}{|l|l|c|l|}
\hline No & \multicolumn{1}{|c|}{ Variabel } & Pernyataan & \multicolumn{1}{c|}{ Sumber } \\
\hline 1. & Kinerja Karyawan & 6 & Florindo dkk (2017) \\
\hline 2. & Motivasi Kerja & 9 & $\begin{array}{l}\text { Juniantara dan Riana } \\
(2015)\end{array}$ \\
\hline 3. & Organizatonal Citizenship Behavior & 5 & Riana, dkk (2017) \\
\hline
\end{tabular}

Sumber: Output smart PLS 3, 2020

\section{HASIL UJI STATISTIK}

Pengujian validitas data dalam penelitian ini diukur menggunakan nilai validitas konvergen, Average Variance Extracted (AVE) dan validitas diskriminan. Nilai loading factor validitas konvergen harus lebih besar dari 0.7 dan jika kurang dari nilai tersebut harus dihapuskan. Dalam penelitian seluruh indikator memiliki nilai loading faktor di atas 0.7 sehingga tidak ada indikator yang dihapuskan. Pengukuran nilai AVE harus lebih besar dari 0.5, dimana nilai AVE kinerja karyawan adalah sebesar 0.754 , motivasi kerja adalah sebesar 0.727, dan organizational citizenship behavior adalah sebesar 0.741. Berdasarkan hasil pengujian discriminant validity, nilai cross loading konstruk yang dituju lebih tinggi daripada cross loading konstruk lain sehingga semua pernyataan pada setiap variabel adalah valid. Pengujian reliabilitas data dalam penelitian ini menggunakan Cronbach's Alpha dan Composite Reliability. Suatu data dapat dikatakan reliabel jika hasil dari cronbach's alpha $>0.6$, dimana nilai cronbach's alpha kinerja karyawan adalah sebesar 0.934, motivasi kerja adalah sebesar 0.953 , dan organizational citizenship behavior adalah sebesar 0.912. Nilai composite reliability harus memiliki nilai 0.7 , dimana nilai composite reliability kinerja 
karyawan adalah sebesar 0.948 , motivasi kerja adalah sebesar 0.960 , dan organizational citizenship behavior adalah sebesar 0.935 .

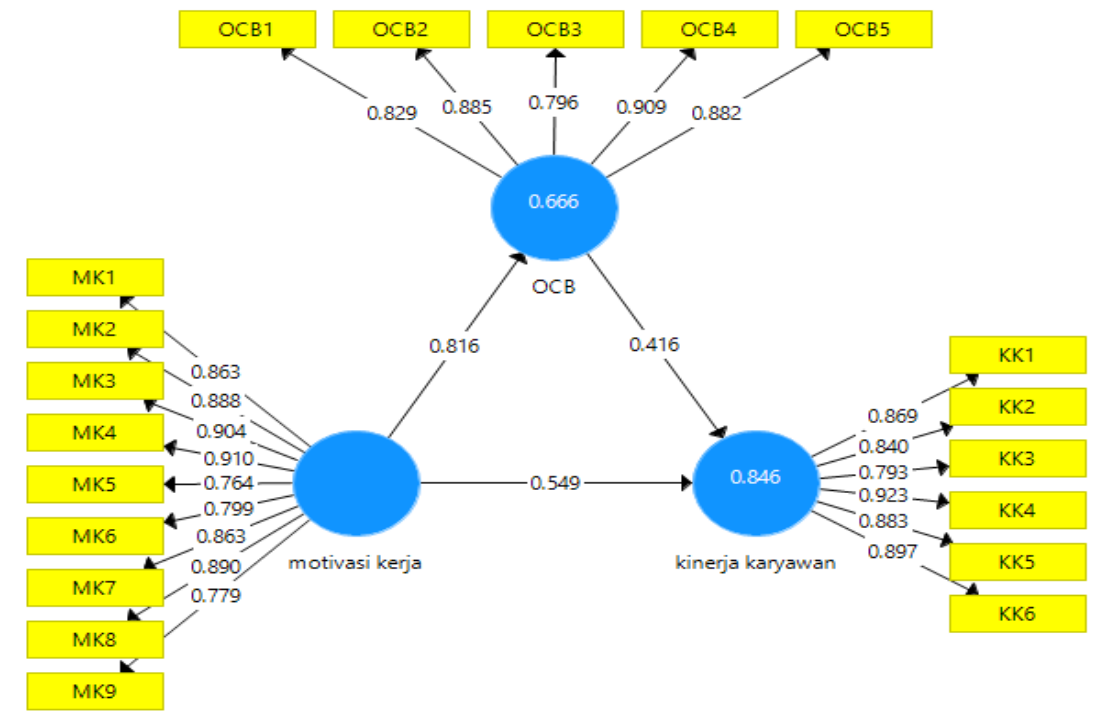

Gambar 2. Hasil PLS Algorithm

Nilai R-square digunakan untuk menghitung besarnya peranan atau pengaruh variabel bebas pada variabel terikat. Pengujian R- Square kinerja karyawan memiliki nilai sebesar 0.846 sedangkan nilai R- Square OCB adalah sebesar 0.666 artinya variabel kinerja karyawan mampu dijelaskan oleh variabel motivasi kerja dan organizational citizenship behavior 84,6\% dan sisanya 15,4\% dijelaskan oleh variabel lain. Variabel organizational citizenship behavior mampu dijelaskan oleh variabel motivasi kerjasebesar 66,6\% dan sisanya 33,4\% dijelaskan oleh variabel lain.

Hasil analisis data dalam uji $\mathrm{Q}^{2}$ digunakan untuk menjelaskan hubungan dari inner model dalam penelitian. Nilai $\mathrm{Q}^{2}$ kinerja kayawan adalah sebesar 0.591 sedangkan nilai $\mathrm{Q}^{2}$ organizational citizenship behavior adalah sebesar 0.455. Hair et al., (2014:145) menyatakan bahwa, konstruk eksogen memiliki relevansi prediktif untuk konstruk endogen yang dapat dinyatakan relevan untuk memprediksi model penelitian apabila memiliki nilai Q lebih dari 0 .

Pengujian Goodness of Fit (GoF) digunakan untuk menunjukkan tingkat kecocokan model yang digunakan dalam suatu penelitian. Untuk dapat melakukan pengujian kecocokan model dalam penelitian ini, nilai GoF (Goodness of Fit) dapat dilihat dari hasil NFI y untuk mengukur model penelitian apakah fit atau tidak. Nilai NFI yang baik adalah $0-1$, dimana hasil NFI penelitian adalah 0.738 yang dapat disimpulkan bahwa ketiga variabel dalam penelitian ini dapat menggambarkan tingkat kelayakan model secara keseluruhan.

Pengujian Hipotesis yang dilakukan dalam penelitian ini untuk dapat menentukan apakah hipotesis-hipotesis yang telah dibuat dalam penelitian ini mempunyai pengaruh yang siginifikan. Signifikansi hipotesis dilihat dari nilai signifikan T-Statistik pada algorithm bootstrapping parameter yang harus lebih dari 1.96 dan p-values harus lebih dari 0,05 sehingga terdapat pengaruh yang signifikan terhadap variabel endogen (Ghozali dan Latan, 2015:42).

Hasil pengujian pada hipotesis pertama (motivasi kerja terhadap kinerja karyawan) memiliki nilai original sample $(\mathrm{O})$ sebesar 0.549 menjelaskan bahwa pengaruh motivasi kerja terhadap kinerja karyawanadalah positif sedangkan nilai t-statistik yang didapat sebesar 6.268 (>1.96) dan p-values sebesar $0.000(<0.05)$ yang berarti signifikan. Dapat disimpulkan bahwa terdapat pengaruh positif dan signifikan antara motivasi kerja terhadap kinerja karyawan sehingga $\mathrm{H}_{1}$ tidak ditolak. 
Untuk hasil pengujian hipotesis kedua (motivasi kerja terhadap organizational citizenship behavior) memiliki nilai original sample $(\mathrm{O})$ sebesar 0.816 menjelaskan bahwa pengaruh motivasi kerja terhadap organizational citizenship behavior adalah positif sedangkan nilai t-statistik yang didapat sebesar 9.698 (>1.96) dan p-values sebesar 0.000 $(<0.05)$ yang berarti signifikan. Dapat disimpulkan bahwa terdapat pengaruh positif dan signifikan antara motivasi kerja terhadap organizational citizenship behavior sehingga $\mathrm{H}_{2}$ tidak ditolak.

Kemudian hasil pengujian hipotesis ketiga (organizational citizenship behavior terhadap kinerja karyawan) memiliki nilai original sample (O) sebesar 0.416 menjelaskan bahwa pengaruh organizational citizenship behavior terhadap kinerja karyawanadalah positif sedangkan nilai t-statistik yang didapat sebesar 4.281 (>1.96) dan p-values sebesar 0.000 $(<0.05)$ yang berarti signifikan. Dapat disimpulkan bahwa terdapat pengaruh positif dan signifikan antara organizational citizenship behavior terhadap kinerja karyawan sehingga $\mathrm{H}_{3}$ tidak ditolak.

Sedangkan hasil pengujian pada hipotesis keempat memiliki nilai original sample $(\mathrm{O})$ direct effect dari motivasi kerja terhadap kinerja karyawansebesar 0.549 sedangkan nilai original sample $(\mathrm{O})$ indirect effect adalah sebesar 0.339 hal ini menunjukkan adanya penurunan nilai original sample sebesar 0.210 dengan adanya organizational citizenship behavior sebagai variabel mediasi. Nilai t-statistik yang didapat sebesar $3.942(>1.96)$ dan pvalues sebesar $0.000(<0.05)$ yang berarti signifikan. Dapat disimpulkan bahwa motivasi kerja merupakan prediktor yang positif untuk kinerja karyawan dengan organizational citizenship behavior sebagai variabel mediasi sehingga $\mathrm{H}_{4}$ tidak ditolak.

Tabel 2. Hasil Pengujian Hipotesis

\begin{tabular}{|l|c|c|c|c|}
\hline \multicolumn{1}{|c|}{ Hipotesis } & $\begin{array}{c}\text { Original } \\
\text { Sample } \\
(\boldsymbol{O})\end{array}$ & T Statistic & PValues & Kesimpulan \\
\hline $\begin{array}{l}\text { Motivasi Kerja } \rightarrow \text { Kinerja } \\
\text { Karyawan }\end{array}$ & 0.549 & 6.268 & 0.000 & Tidak ditolak \\
\hline Motivasi Kerja $\rightarrow$ OCB & 0.816 & 9.698 & 0.000 & Tidak ditolak \\
\hline $\begin{array}{l}\text { OCB Kinerja } \\
\text { Karyawan } \rightarrow \text { OCB } \rightarrow\end{array}$ & 0.416 & 4.281 & 0.000 & Tidak ditolak \\
\hline $\begin{array}{l}\text { Motivasi Kerja } \rightarrow \text { OCak ditolak } \\
\text { Kinerja Karyawan }\end{array}$ & 0.339 & 3.942 & 0.000 & Tidak \\
\hline
\end{tabular}

Sumber: Output smart PLS 3, 2019

\section{DISKUSI}

Hasil analisis menunjukkan bahwa $\mathrm{H} 1$ tidak ditolak, yaitu motivasi kerja memiliki pengaruh yang positif dan signifikan terhadap kinerja karyawan.Karyawan dengan motivasi kerja yang tinggi akan menghasilkan kinerjayang tinggi pula. Motivasi merupakan dorongan yang ada dalam diri seseorang untuk melakukan suatu tindakan dan pekerjaan. Motivasi timbul karena adanya pemenuhan dari kebutuhan- kebutuhan karyawan dari perusahaan. Pemenuhan kebutuhan ini dapat mendorong gairah karyawan untuk bekerja dan melakukan tugas yang diberikan oleh perusahaan sebagai bentuk timbal balik atau balas jasa dari karyawan untuk perusahaannya.Hasil ini sesuai dengan penelitian Juniantara dan Riana (2015)bahwa motivasi kerja memiliki hubungan yang positif dan signifikasn terhadap kinerja karyawan. 
Untuk hasil analisis berikutnya menunjukkan bahwa $\mathrm{H} 2$ tidak ditolak dimana menunjukkan bahwa motivasi kerja memiliki pengaruh yang positif dan signifikan terhadap organizational citizenship behaviour. Karyawan yang memiliki motivasi kerja tinggi mempunyai organizational citizenship behavior yang tinggi pula. Karyawan dengan OCB tinggi biasanya akan dengan sukarela melakukan pekerjaan - pekerjaan di luar tugas formalnya. Selain itu karyawan dengan OCB tinggi akan memiliki sikap peka terhadap sesama, nilai berbasis moral, dan komitmen untuk melakukan perubahan.Hasil ini sesuai dengan penelitian yang telah dilakukan oleh Hapsari (2015) bahwa terdapat pengaruh yang positif dan signifikan antara motivasi kerja terhadap organizational citizenship behavior.

Hasil analisis menunjukkan bahwa $\mathrm{H} 3$ tidak ditolak dimana organizational citizenship behavior memiliki pengaruh yang positif dan signifikan terhadap kinerja karyawan. Oleh karena itu karyawan dengan organizational citizenship behavior yang tinggi mempunyai kinerjayang tinggi pula. Organizational Citizenship Behavior memainkan peran penting dalam penyelesaian pekerjaan yang lebih cepat dan optimalisasi sumber daya. OCB diyakini mampu mendorong efektivitas fungsi perusahaan. Perusahaan dimana memiliki karyawan yang dapat melakukan pekerjaan melebihi job description terbukti memiliki banyak keunggulan dibanding perusahaan lain.Hasil ini sesuai dengan penelitian yang telah dilakukan oleh Lestari dan Ghaby (2018) dimana mendapatkan hasil bahwa organizational citizenship behavior memiliki pengaruh yang positif yang signifikan terhadap kinerjakaryawan.

Sedangkan hasil analisisselanjutnya menunjukkan bahwa $\mathrm{H} 4$ tidak ditolak dimana motivasi kerja memiliki pengaruh yang positif dan signifikan untuk kinerja karyawandengan organizational citizenship behavior sebagai variabel mediasi. Motivasi kerja dapat mendorong karyawan untuk menghasilkan kinerja terbaiknya, dimana akan menimbulkan rasa senang dalam diri karyawan dalam melakukan pekerjaannya dan akan menimbulkan rasa inisiatif dari dalam diri untuk melakukan pekerjaan tambahan yang bukan merupakan tugas formal dari perusahaan.Hasil ini sesuai dengan penelitian yang dilakukan oleh Widyastuti dan Palupiningdyah (2015) dimana menemukan bahwa motivasi kerja memiliki pengaruh yang positif dan signifikan terhadap kinerja karyawan dengan OCB sebagai mediasi.

\section{KESIMPULAN}

Berdasarkan seluruh hasil pengujian hipotesis dalam penelitian ini, maka diketahui bahwa:

1. Motivasi Kerjamemiliki pengaruh yang positif dan signifikan terhadap Kinerja Karyawan.

2. Motivasi Kerjamemiliki pengaruh yang positif dan signifikan terhadap Organizational Citizenship Behavior.

3. Organizational Citizenship Behavior memiliki pengaruh yang positif dan signifikan terhadap Kinerja Karyawan.

4. Motivasi Kerja memiliki pengaruh yang positif dan signifikan terhadap Kinerja Karyawan dengan Organizational Citizenship Behavior sebagai variabel mediasi.

Maka daripada itu, Untuk mempertahankan kinerja karyawan, perusahaan dapat memberikan motivasi misalnya pemberian perhargaan bagi karyawan berprestasi dan menciptakan lingkungan kerja yang baik, membuat suatu wadah untuk menampung aspirasi karyawan dan membuat kebijakan baru dimana kesejahteraan dan kebutuhan karyawannya tetap diperhatikan. Pemberian motivasi dapat mendorong karyawan untuk bekerja lebih baik lagi sehingga dapat mencapai tujuan visi dan misi dari perusahaan. 


\section{DAFTAR PUSTAKA}

A.A. Anwar Prabu Mangkunegara. 2015. Manajemen Sumber Daya Manusia Perusahaan, Bandung: PT Remaja Rosda Karya.

Aamodt, M. G. 2010. Industrial Organizational Psychology: An Appied Approach. Sixth Edition. USA: Wadsworth Cencange Learning.

Bangun, Wilson. 2012. "Manajemen Sumber Daya Manusia". Jakarta: Erlangga.

Dessler, Gary. 2017. Manajemen Sumber Daya Manusia. Jakarta: Salemba Empat.

Garson, G. D. 2016. Partial Least Square: Regression \& Structural Equation Models.

USA: Statistical Associates Blue Book Series

Ghozali, Imam, Hengky Latan. 2015. Konsep, Teknik, Aplikasi Menggunakan Smart PLS 3.0 Untuk Penelitian Empiris. BP Undip. Semarang

Hussein, A. S., (2015). Penelitian Bisnis dan Manajemen Menggunakan Partial Least Square (PLS) dengan SmartPLS 3.0. Universitas Brawijaya.

Lestariningtyas, E. (2016). Peran Komitmen Organisasi Sebagai Variabel Intervening Antara Kepuasan Kerja dan Organizational Citizenship Behavior (OCB) Pada Karyawan PT. Coca-Cola Distribution Indonesia, Surabaya. Jurnal Ilmu Manajemen, 4(3), 1-10.

Mejia, Luis R. Gomez, dkk. 2004. Human Resource Management. Person prenticeHall

Mondy, R.W., Noe, R.M., Premesux, S.R., 1996. Human Resource Management ～(5rded), Massachusetts, Allyn and Bacon.

Moeheriono. 2012. "Pengukuran Kinerja Berbasis Kompetensi”. Jakarta: Raja Grafindo Persada.

Morrison, E. W. (1994). Role Definitions And Organizational Citizenship Behavior: The Importance Of The Employee's Perspective. The Academy of Management Journal, 37 (6), 1543-1567.

Organ, D. W., P. M. Podsakoff, S. B. MacKenzie. 2006. Organizational Citizenship Behavior: Its Nature, Antecedents, and Consequences. USA: Sage Publications, Inc.

Rita, Marcy dkk. 2017. Moderating Effect of Organizational Citizenship Behavior on The Effect of Organizational Commitment, Transformational Leadership and Work Motivation on Employee Performance. International Journal of Law and Management, 60 (4), 953-964.

Robbins, Stephen P \& Judge, Timothy A. 2013. Organizational Behavior Edition 15. New Jersey: Pearson Education

Sekaran, U. \& Bougie, R. (2016). Research Methods for Business (6th ed). Southern Gate, Chichester, West Sussex: John Wiley \& Sons, Ltd

Supriyanto, Achmad Sani dan Vivin Maharani. 2013. Metode Penelitian Sumber Daya Manusia Teori, Kuisioner, dan Analisis Data. Malang: UIN-Malang Press.

Viswesvaran, C. dan Ones, D.S. 2000. "Perspectives on models of job performance". International Journal of Selection dan Assessment, Vol. 8 No. 4, pp. 216226.

Wirawan. 2009. Evaluasi Kinerja Sumber Daya Manusia Teori Aplikasi dan Penelitian. Jakarta. Penerbit: Salemba Empat. 